\title{
FACTORS INFLUENCING FARMERS' ADOPTION OF ECOLOGICAL RECONVERSION AGRI-ENVIRONMENTAL SCHEMES IN MOUNTAIN OLIVE GROVES
}

\author{
$\underline{\text { Rubén Granado-Díaz }}^{\text {a*, Anastasio J. Villanueva }}{ }^{\mathrm{a}, \mathrm{b}}$ and José A. Gómez-Limón ${ }^{\mathrm{a}}$ \\ ${ }^{a}$ WEARE-Water, Environmental and Agricultural Resources Economics Research Group, University of \\ Cordoba, (g82grdir@uco.es, jglimon@uco.es, Cordoba); ${ }^{b}$ Institute of Agricultural Research and Training \\ (IFAPA), Centre Camino de Purchil, (anastasioj.villanueva@juntadeandalucia.es, Granada)
}

\begin{abstract}
Mountain olive groves are characterized by low profitability, mainly due to their location in high steepslope areas with poor, shallow soils. Consequently, they present a high risk of abandonment of the productive activity, which would be eventually associated with high potential environmental and sociocultural losses. As an alternative, an ecological reconversion scheme is proposed to increase the provision of ecosystem services from this agroecosystem while reducing the socio-economic impacts related to the abandonment. Two alternative schemes are proposed, which differ in the possibility or not of harvesting the olive production. A double-bounded contingent valuation exercise is used in a sample of Andalusian mountain olive growers to assess their willingness to accept (WTA) for participating in these schemes, using a difference-in-utility model with a linear utility function with correlation between the participation choices in the two schemes as econometric specification. The results show high levels of mean WTA, higher for the scheme precluding harvesting, indicating that higher levels of payment are needed to get some acceptance from farmers. Results also show that structural (e.g., yield) and attitudinal factors (e.g., opinion about setting-aside low productivity olive groves for environmental reasons), among others, significantly influence farmers' WTA for these schemes.
\end{abstract}

Keywords: Agri-environmental schemes, Production abandonment, Willingness to accept, Doublebounded contingent valuation, Andalusia (Spain).

\section{Introduction}

The mountainous olive groves (MOG) represent one of the most characteristic olive groves systems. It is located in areas with important agro-climatic constraints (low soil fertility, steep orography, high altitude, remote location, etc.). These circumstances involve low yields and high production costs due to mechanization difficulties, resulting in low private economic profitability, which in many cases becomes negative. The low economic profitability of this agrosystem results in a high risk of abandonment. This situation of economic unsustainability and risk of abandonment is likely to worsen in the near future if the expectations of low olive oil prices due to the increase in supply and/or reduction of Common Agricultural Policy (CAP) support after the next reform are confirmed.

The abandonment of MOG farms would have important impacts, both socioeconomic and environmental. It is well documented that the abandonment of agricultural activities usually entails income and employment losses in rural areas where they are located, which are usually remote regions without economic alternatives.

From an environmental point of view, the existing literature points out that the abandonment of MOG could produce an improvement in the levels of provision of public goods biodiversity, soil conservation, and carbon sequestration [Villanueva et al. (2018)]. However, there is also evidence that uncontrolled abandonment of MOG could have a negative environmental impact in the form of increased fire risk, which could ultimately lead to environmental degradation [Rocamora-Montiel et al. (2014)].

Taking into account the low private economic profitability of MOG and the potential environmental benefits derived from their abandonment, the idea of promoting ecological reconversion strategies is gaining widespread support [Granado-Díaz et al. (2020)]. The purpose of these initiatives would be to encourage an "orderly" abandonment of the productive activity trying to improve the provision of environmental public goods, while minimizing the negative impact that this could have on the vitality of the rural areas. In this sense, one of the best instruments available within the CAP to achieve both objectives would be the implementation of agri-environmental schemes [Gómez-Limón et al. (2019)].

Within this context, the objective of this research is to evaluate the willingness to participate of MOG growers in agri-environmental schemes aiming at ecological reconversion based on a controlled and restorative wilderness of their olive farms, considering different levels of abandonment of production (partial and complete) and different levels of payment. For this purpose, the contingent valuation technique was used on a representative sample of MOG growers in Andalusia. 


\section{Methodological approach}

\subsection{Case study: ecological reconversion scheme in mountain olive groves}

For this research, MOG has been defined as those rainfed olive groves located in areas with slopes equal to or higher than $15 \%$ and average yields equal to or lower than 2,500 $\mathrm{kg}$ of olives per hectare. According to the information available, the MOG system thus defined covers an area of 211,000 hectares in Andalusia, representing about $14 \%$ of the Andalusian olive grove area [Villanueva et al. (2018)].

Two possible alternative schemes of ecological reconversion are defined. In the first scheme, productive ecological reconversion, the implementation of cover crops over the total area would be required, and soil tillage and biocides application would be prohibited, aiming to maximize the biodiversity and minimize the risk of erosion. To reduce fire risks, one-time cover crops mowing would be required to be done by June, and pruning would be made once every five years. This scheme does not place any limitations on olive harvesting. The second scheme, called complete ecological reconversion, is more demanding since, in addition to the above-mentioned requirements, it imposes a ban on olive harvesting to increase food availability for the fauna, thus enhancing biodiversity.

The promotion of this reconversion would require an economic compensation (agri-environmental payment for the income loss) to those growers who voluntarily agreed to implement these changes in their farms. Logically, the agri-environmental payment of the scheme with higher environmental requirements (complete ecological reconversion) should be higher than that of the scheme with lower requirements (productive ecological reconversion), since income losses would be higher.

\subsection{Contingent valuation exercise}

To analyze the acceptance of the proposed schemes, the double-bounded dichotomous choice contingent valuation method was used [Hanemann et al. (1991)]. The interviewees were given a detailed explanation of the scheme requirements corresponding to the productive ecological reconversion scheme, which could be accepted by the interviewees in exchange for a compensation established in the first offer of $€ 250 /$ ha/year. Depending on whether the response was negative (the interviewee did not accept the scheme in exchange for this compensation) or positive (the interviewee did accept the scheme), the second offer of $€ 375$ or $€ 125 /$ ha-year, respectively, was made. In any case, farmers were informed that this scheme would be compatible with the current basic and green payments, as is the case with the rest of the agrienvironmental schemes. Afterward, the complete ecological reconversion scheme was explained and then similar valuation questions were asked, using $€ 500 / \mathrm{ha} /$ year as the first offer, and $€ 750$ or $€ 250 / \mathrm{ha} /$ year as second offers. The payment levels were set considering the schemes currently implemented in Andalusian MOG, which include similar (although less demanding) requirements.

\subsection{Econometric specification}

The double-bounded contingent valuation exercise used in this investigation allows for four possible results as a combination of the two bids offered: accept both bids (yes,yes or $y, y)$, accept the first and reject the second (yes,no or $y, n)$, reject the first and accept the second (no,yes or $n, y)$ or reject both bids (no,no or $n, n)$. From these possible responses, farmer's WTA can be bounded as follows:

$$
\begin{gathered}
W T A_{y, y} \leq A_{l} \\
A_{l}<W T A_{y, n} \leq A_{i} \\
A_{i}<W T A_{n, y} \leq A_{u} \\
W T A_{n, n}>A_{u}
\end{gathered}
$$

where $W T A_{y, y}, W T A_{y, n}, W T A_{n, y}$, and $W T A_{n, n}$ represents the WTA associated with each of the possible combinations of answers to both bids offered, $A_{i}$ is the initial bid ( $€ 250$ and $€ 500 /$ ha year in the first and second schemes, respectively), $A_{l}$ is the lower bid, offered after the first bid is accepted ( $€ 125$ and $€ 250 /$ ha year in the first and second schemes, respectively), and $A_{u}$ is the upper bid, offered after the first bid is rejected ( $€ 375$ and $€ 750 /$ ha year in the first and second schemes, respectively).

In the interviews administered, farmers were asked about two consecutive exercises of contingent valuation for the two schemes. In that situation, farmers' WTA for participation in both schemes would be:

$$
W T A_{1}=\frac{\alpha_{1} x_{1}+\eta_{1}}{\beta_{1}} ; W T A_{2}=\frac{\alpha_{2} x_{2}+\eta_{2}}{\beta_{2}}
$$

with subindexes 1 and 2 representing choice situations related to schemes involving partial and complete ecological reconversion of olive groves, respectively, $\alpha$ and $\beta$ being the vectors of parameters for the farm/farmer characteristics and the monetary compensation, respectively, and $\eta$ being random term including the unobserved characteristics of the farm, the farmer, and the scheme. As both schemes shared most of the practices, it can be reasonably assumed that farmers' choices with regard to participating in the schemes proposed are correlated, and therefore $\eta_{1}$ and $\eta_{2}$ would follow a bivariate normal distribution. 
The values of $\alpha_{1}, \beta_{1}, \alpha_{2}$, and $\beta_{2}$ of the WTA function for participating in schemes 1 and 2 , and the bivariate normal's Rho parameter of this difference-in-utility model, are obtained using the maxLik R package.

\subsection{Data gathering}

A multistage clustering procedure was followed to extract the sample of olive growers interviewed. First, the Andalusian agricultural districts where the presence of MOG is significant (more than 10,000 hectares) and predominant (more than $50 \%$ of the olive grove area) were selected. As a result, the sampling focused on the districts of La Sierra and Los Pedroches (Córdoba), and Sierra Norte (Seville), which aggregately account for $27 \%$ of the Andalusian MOG. Secondly, the municipalities to be sampled within each region were randomly selected. Thirdly, a random route procedure was finally used in the selected municipalities, carrying out personal interviews with farmers in various public places and times of the day. The interviews were conducted between October and December 2016, totaling 261 interviews. For more information about the sample and the questionnaire, consult Granado-Díaz et al. (2020).

\section{Results and discussion}

Table 1 shows the results of the model and the mean WTA estimation for both schemes. As can be seen, the model is highly significant. First, the Rho parameter of the bivariate normal is significant and positive, indicating that farmers' participation choices in the schemes considered are correlated-thus giving support to the modeling approach used. As shown in the table, several significant determinants of choice are identified, with three of them affecting both schemes, which are: farm yield (YIELD), the use of soil cover in more than $50 \%$ of the area (SC50), and the absence of farm succession (NOSUCC). The first has a positive sign for both schemes, indicating that the higher the yield of the farm the higher the farmer's WTA for participation in both schemes. This clearly relates to the opportunity costs of participation. In the case of SC50, the variable is related to the implementation of environmentally friendly agricultural practices, showing that farmers who already use these practices would require a lower payment. Finally, in the case of NOSUCC, when the farmer has no sure successor, s/he would be more willing to participate in a scheme like the proposed, which would affect the farm production capacity.

In addition, for the first scheme, the variable INC20 (i.e., which takes the value 1 when more than $20 \%$ of the total income of the farmer comes from the MOG farm) also results significant and negative, which indicates that those farmers who are more dependent on the MOG income are less willing to participate in the scheme. For the second scheme, other significant determinants of participation choice are NOREC (farmer's opinion about setting aside low productivity olive groves for environmental reasons) and NOOAC (farmers with the lack of other economic activities as the main motivation to continue managing the MOG farm), both of them negatively affecting WTA with the former related to farmers' environmental attitudes and the latter to socio-economic attitudes.

With regard to mean WTA estimates, the result for the partial ecological reconversion is about $70 \%$ of the complete reconversion scheme, indicating that farmers logically require a higher compensation for the second, more stringent scheme. On the other hand, it can be seen the different ways in which farm and farmer characteristics affect the total WTA for each scheme. In the first scheme, farm, and farmer characteristics (especially YIELD and SC50) have an important weight in the total WTA, while in the second scheme most of the WTA is determined by the constant term.

Table 1. Results of the model and mean WTA estimations

\begin{tabular}{|c|c|c|c|c|c|}
\hline Scheme & Variable & Coefficient & Std. Error & $\begin{array}{c}\text { Mean WTA } \\
(€ / h a)\end{array}$ & $\begin{array}{c}\text { Confidence interval } \\
(95 \%)\end{array}$ \\
\hline \multirow{7}{*}{$\begin{array}{l}\text { Partial ecological } \\
\text { reconversion }\end{array}$} & YIELD & $0.0006^{* * *}$ & 0.0001 & $542.16^{\text {**** }}$ & $(317.45-810.04)$ \\
\hline & SC50 & $-1.0221^{* * *}$ & 0.2372 & $-349.81^{\text {**** }}$ & $(-522.59--206.71)$ \\
\hline & INC20 & $0.4212^{* *}$ & 0.1467 & $150.18^{* *}$ & $(61.27-246.43)$ \\
\hline & NOSUCC & $-0.8328^{* *}$ & 0.2536 & $-60.49^{* * * *}$ & $(-98.48--28.68)$ \\
\hline & BID & $0.0018^{\text {*** }}$ & 0.0003 & & \\
\hline & Constant & $0.9642^{* *}$ & 0.3495 & $550.81^{* *}$ & $(241.96-882.02)$ \\
\hline & Total & & & 832.83 $^{* * * *}$ & $(684.77-1,035.89)$ \\
\hline \multirow{8}{*}{$\begin{array}{l}\text { Complete } \\
\text { ecological } \\
\text { reconversion }\end{array}$} & YIELD & $0.0007^{\text {*** }}$ & 0.0001 & $467.23^{* * *}$ & $(295.41-656.09)$ \\
\hline & SC50 & $-0.6302^{* *}$ & 0.2391 & $-172.01^{* * *}$ & $(-287.55--64.44)$ \\
\hline & NOREC & $-0.1372^{* *}$ & 0.0488 & $-175.69^{* * *}$ & $(-283.64--73.63)$ \\
\hline & NOOAC & $-0.1233^{* *}$ & 0.0466 & $-108.20^{* *}$ & $(-177.49--41.95)$ \\
\hline & NOSUCC & $-0.5083^{*}$ & 0.2484 & $-29.44^{*}$ & $(-54.66--5.36)$ \\
\hline & BID & $0.0022^{* * * *}$ & 0.0003 & & \\
\hline & Constant & $2.6447^{* * * *}$ & 0.4365 & $1,205.26^{* * * *}$ & $(921.01-1,518.35)$ \\
\hline & Total & & & $1,187.15^{\text {**** }}$ & $(1,065.89$ - 1,338.07) \\
\hline Rho & & $0.7807^{* * *}$ & 0.0520 & & \\
\hline
\end{tabular}


From these values, it is possible to estimate the farmers' probability of accept to participate in the schemes considered, as is shown in Figure 1. In this figure, the payment levels of $€ 100, € 350$, and $€ 900 /$ ha year are shown, the first two corresponding (approximately) to the current agri-environmental payment, and the last one to the maximum premium allowed in the Regulation (EU) $n^{\circ} 1305 / 2013$. As can be seen, a little more than $5 \%$ of farmers would accept to participate in the partial reconversion scheme in the absence of any payment, indicating that these farmers already do these agricultural practices, while in the complete reconversion program this percentage is almost null. With the lowest payment, only $9.5 \%$ of farmers would participate in the partial reconversion scheme, while just $0.8 \%$ of farmers would do so for the complete reconversion one. For a payment of $€ 350 /$ ha year, these percentages would increase to $19.4 \%$ and $3.2 \%$, respectively. Finally, for the maximum payment the $54.6 \%$ of farmers would accept to participate in the partial reconversion scheme, and $26.3 \%$ in the complete reconversion scheme.

Figure 1. Probability of acceptance of participation in the partial and complete ecological reconversion schemes as a function of the payment

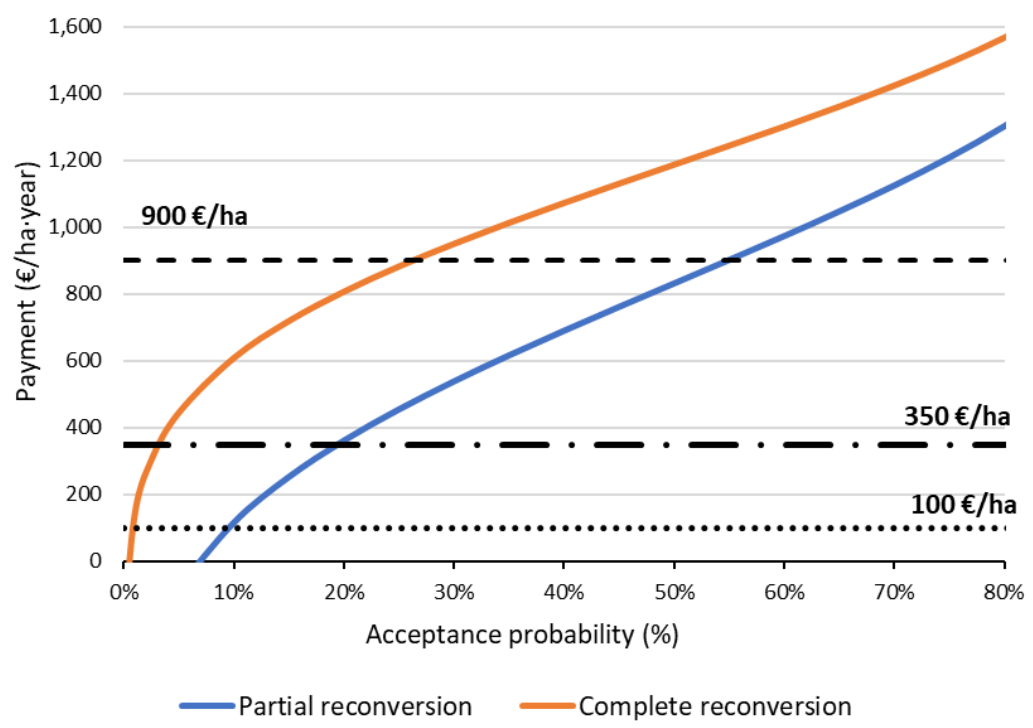

\section{Concluding remarks}

The ecological reconversion of MOG would require payments that remarkably exceed the current agrienvironmental payments for olive groves, especially for the complete reconversion (without harvesting), in which farm and farmers' characteristics seem to be less determinant of the farmer WTA. The results are useful for policymaking, as they provide valuable information for a better scheme targeting (e.g., by identifying those farmers who require lower payments to participate).

\section{References}

Gómez-Limón, J.A., Gutiérrez-Martín, C. y Villanueva, A.J. (2019). "Optimal design of agrienvironmental schemes under asymmetric information for improving farmland biodiversity". Journal of Agricultural Economics, 70(1): 153-177.

Granado-Díaz, R., Villanueva, A.J. y Gómez-Limón, J.A. (2020). “Resultaría económicamente eficiente un programa de reconversión ecológica para el olivar de montaña andaluz?”. Economía Agraria y Recursos Naturales (Agricultural and Resource Economics), 20(1): 103-129.

Hanemann, M., Loomis, J. y Kanninen, B. (1991). "Statistical efficiency of double-bounded dichotomous choice contingent valuation". American Journal of Agricultural Economics, 73(4): 1255-1263.

Rocamora-Montiel, B., Glenk, K. y Colombo, S. (2014). "Territorial management contracts as a tool to enhance the sustainability of sloping and mountainous olive orchards: Evidence from a case study in Southern Spain". Land Use Policy, 41: 313-325.

Villanueva, A.J., Granado-Díaz, R. y Gómez-Limón, J.A. (2018). La producción de bienes públicos por parte de los sistemas agrarios. UCOpress, Editorial Universidad de Córdoba, Córdoba. 